\section{International Scientific Journal Theoretical \& Applied Science}

\author{
p-ISSN: 2308-4944 (print) e-ISSN: 2409-0085 (online) \\ Year: $2018 \quad$ Issue: 03 Volume: 59
}

Published: $30.03 .2018 \quad$ http://T-Science.org
Gulchexra Gulamjanovna Gaffarova doctor of Philosophy (PhD), senior scientific researcher, National University of Uzbekistan, Tashkent, Uzbekistan gulchehra_3@mail.ru

Mahbuba Nurullayevna Abdulleva Doctor of Philosophy, Professor, National University of Uzbekistan, Tashkent, Uzbekistan

SECTION 30. Philosophy.

\title{
SELF-ORGANIZATION IN THE CONTEXT OF EPISTEMOLOGY
}

Abstract: The process of cognition is a relentless search for new methods and approaches to the knowledge of a complex, diverse world. The vector of the development of the cognitive apparatus is aimed at the knowledge of a more complex, interrelated, interdependent world, the formation of new methods of methodological guidelines. Increasing complexity of the surrounding world poses a problem on what the behavior of complex systems depends?

The concept of self-organization, emerged as an interdisciplinary approach, shows that in the world all are interconnected, interdependent. This article analyzes the problems of self-organization in the process of cognition (epistemology).

Key words: autopoiesis, autopoiesis, autophagy, system, dissipative system, approach, disciplinary approach, system approach, interdisciplinarity, interdisciplinary approach, cognition, self-organization, synergetics, synergetic approach, complex systems, structure.

Language: Russian

Citation: Gaffarova GG, Abdulleva MN (2018) SELF-ORGANIZATION IN THE CONTEXT OF EPISTEMOLOGY. ISJ Theoretical \& Applied Science, 03 (59): 164-169.

Soi: http://s-o-i.org/1.1/TAS-03-59-27 Doi: crossef https://dx.doi.org/10.15863/TAS.2018.03.59.27

\section{САМООРГАНИЗАЦИИ В КОНТЕКСТЕ ЭПИСТЕМОЛОГИИ}

Аннотация: Процесс познание - это неустанный поиск новых методов и подходов познании сложного, многообразного мира. Вектор развития познавательного аппарата направлен на познание усложняюшегося, взаимосвязанного, взаимообусловленного мира, формированием новых методов методологических установок. Все возрастающая сложности окружающегося мира ставит проблему от чего зависит поведение сложных систем?

Концеепция самоорганизации, возникла как междисциплинарный подход, показывает что в мире все взаимосвязаны, взаимообусловлены. В этом статье анализируется проблемы самоорганизации в процесс познание (эпистемологии).

Ключевые слова: аутопоэзис, аутопоэзной систем, аутофагии, система, диссипативная система, подход, дисииплинарного подхода, системный подход, междисцииплинарность, междисциплинарный подход, познания, самоорганизации, синергетика, синергетический подход, сложные системы, структура.

\section{Введение.}

Современный познавательный аппарат в соответствии с изучением нелинейных процессов природы пополнился теорией сложных систем (синергетика), которая позволяет исследовать неисследованные стороны нелинейного мира. Законы, закономерности отражающие процессы линейного мира пополнились новыми научными методами, подходами нелинейного мира. Изучение этого мира не продуктивно в аспекте только дисциплинарного подхода, который дополняется междисциплинарным подходом. Так, например, синергетический подход, в столь разных по природе живой и неживой природе позволил установить нечто общее между ними.

\section{Основная часть.}

Процесс образования новых структур в открытых системах подчинены общим закономерностям. С точки зрения синергетики и творческие возможности предстают в новом виде. «В мозге происходит своего рода фазовый переход, множество прежде никак не связанных между собой детали неожиданно становятся частицами вполне упорядоченного и преисполненного глубочайшего смысла единства 
речь в данном случае идет о процессах аналогичных тем, что уже известны нам из других областей синергетики. В результате той или иной флуктуации («озарения» или вспышки) возникает новый параметр порядка (новая идея) благодаря которой нам и удаётся найти взаимосвязь между отдельными деталями и упорядочить их, подчинив себе. Однако все это происходит благодаря самоорганизации самоорганизации наших мыслей в данном случае» [[12, с.232]].

Синергетика, как междисциплинарное направление е научных исследований позволяет исследовать общие закономерности процессов перехода от хаоса к порядку и обратно в открытых нелинейных системах физической, химической, биологической, экономической, социальной и других сферах. «Междисциплинарность означает прежде всего, кооперацию различных областей, циркуляцию общих понятий для понимания некоторого явления» [[2, с.28]].

Междисциплинарность

содружество различных наук, стремящихся решить свои проблемы совместно, но при этом отдавая приоритет конкретной дисциплинарной науке. Так, например Э. Морен отмечает, что «междисциплинарность может просто означать только и просто то, что различные дисциплины садятся в ООН исключительно для того чтобы заявить о своих собственных национальных правах и своем суверенитете по отношению к посягательствам соседа. Но междисциплинарность может стремится к обмену и кооперации, в результате чего междисциплинарность может становится чем-то органическим» [[8, с.133]].

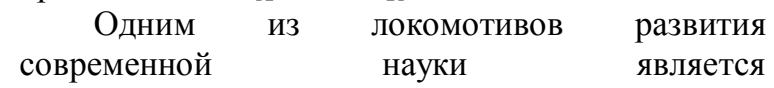
междисциплинарный подход, который имеет возможность, как для углубленного так и для расширения научных исследований.

Концепция самоорганизации, возникла как междисциплинарный подход, основываясь на то, что в мире все на идеи, взаимосвязано, взаимообусловлено.

Основу синергетического подхода составляет системной подход. «Синергетика опирается на очень разные дисциплины, среди которых не только физика, химия и биология, но и также социология и экономика, можно поэтому ожидать, что открытые и описанные синергетикой закономерности уже так или иначе будут представлены в различных областях науки, и у нас появится возможность увидеть возникновение в свете синергетики новой, единой картины мира, составленной, подобно мозаике, из множества отдельных, собранных наукой фактов» [[12, с.25]].
Объект изучения синергетики - механизм перехода хаоса в порядок, процесс самоорганизации, обуславливающий возникновение нового.

Устойчивость и неустойчивость, порядок и хаос являются компонентами, которые составляют основу синергетической картины мира.

В истории науки представления об основах, составляющих основу мироздания можно проследить в основном два направления. Консервативная система, в которой считалась, что существует первичный элемент не подверженный изменениям (Фалес и др.). Данная концепция составляла основу классической науки. Результаты исследований свидетельствуют о том, что наряду с тем, что система консервативна она еще обратима во времени [[9, с.60]].

Платон был убежден в том, что постоянство так и изменчивость являются составными частями реальности. По Гераклиту реальность есть процесс, арена борьбы и самоорганизации разных сущностей. «Этой космос, тот же самый для всех, не создал никто из богов, ни из людей, он всегда был, есть и будет вечно живым огнем, мерами разгорающимся и мерами погасающим» [[7, c.8]].

Проблема самоорганизации живых систем, как подчеркивает Ф.Капри в кн. «Паутина жизни. Новое научное понимание живых систем», рассматривалась и в философии И.Канта. Его идеи в какой-то степени идентичны современным воззрениям на процесс самоорганизации в живых системах. В произведении «Критика практического разума, он подчеркивает что, организмы в отличие от машины, представляют собой самовоспроизводящиеся, самоорганизующиеся целостности. В машине, согласно Канту, части существуют только друг для друга в смыли поддержки друг друга в рамках функциональной целостности. В организме части существуют часто с помощью друг друга в смысле создания друг друга» [[1]].

Идеи о взаимосвязи, взаимозависимости можно найти в этих концепциях, но преобладает консерватизм. Но эти абстрактные идеи были лишь умозрительными рассуждениями или индуктивными догадками, ни теоретической ни экспериментальной базы не было.

Второй подход - диссипативная система. Она не консервативна (энергия в ней не сохраняется), а открыта. Обычно оно содержит внешний управляющий параметр, который можно менять и прослеживать переход к хаосу» [[4, с.84]].

Исследуя переход от нормального света к лазерному, Хакен понял, что этот переход служит 
примером самоорганизации систем далеких от равновесия.

Что такое самоорганизация, какую систему можно назвать самоорганизующейся?

По мнению Г.Хакен, самоорганизующаяся система «если она без специфического воздействия извне обретает какую-то пространственную, временную или функциональную структуру. Под специфическим внешним воздействием мы понимаем такое, которое навязывает системе структуру или функционирование. В случае же самоорганизации система испытывает извне не специфического воздействие. Например, жидкость, подогреваемая снизу, совершенно равномерно обретает в результат самоорганизации структуру, образуя шестиугольные ячейки» [[11, с.28]].

В самоорганизующихся системах без специфического воздействие используются внутренние возможности в результате действия которых возникают более сложные и более совершенные структуры. Понятие «структура», указывает на упорядоченность системы, показывающая относительную устойчивости между элементами системы. Динамика системы определяется ее структурой. Для формирования новых структур система должна быть: далеко от равновесного состояния; необходим непрерывный поток материи и энергии сквозь систему; нелинейная взаимосвязь между элементами системы, которая характеризуется функционированием петли обратной связи. Образование новых структур и их функционирование происходит в процессе развития, обучения и т.д. Почему? Формирование и функционирование новых структур показывает адаптационные возможности системе. Возникновение новых структур, дает возможность системе адаптироваться и окружающей среде, т.е. системе реагирует на изменение внешней среды. Все это определенных условиях приводит к качественным изменением системы. Структурные изменения его времени могут привести к распаду системы, а альтернатива структурные изменения основа совершенствование системы, т.е. структурные изменений основа качественных преобразоваться системы, их можно рассматривать как эволюцию системы.

Изменение структуры, возникновение новых структур являются всеобщей закономерностью, как в области неживой, живой и ментальных сферах.

Систем, происходит за счет постоянного прохождения через них потока энергии и вещества. «Знакомыми примерами являются живые системы, такие как растения и животные, которые питаются» биохимической энергией.
Процесс переработки этой энергии может приводить к образованию макроскопических структур - рост растений, миграции животных и т.д. Однако такое возникновение порядка никоим образом не присуще только живым системам. Этот тип диссипативности (необратимой) самоорганизации вдали от термодинамического равновесие, которой можно найти не только в биологии, но и в физике, и в химии» [[7, с.92-93]].

$$
\text { Необратимость в классической }
$$
термодинамике всегда ассоциировалась с рассеянием энергии и потерями. Диссипативные структуры по Пригожину показывают, что в живых системах функционирующих в условиях, удаленных от равновесия необратимость играет конструктивную роль. Формирование и функционирование диссипативных структур показывают, стремление системы и устойчивому состоянию, происходит при условии постоянного потока энергии и есть своеобразный синтез порядка и хаоса. Устойчивость системы осуществляется за счет порядке в системе и хаоса в окружающей среде.

Образовавшиеся равновесных системы можно изолировать и поддерживать долгое время без дальнейшего взаимодействие с внешней средой. Как подчеркивает И.Пригожин «вдали от равновесия могут спонтанно возникать новое типы структур. В сильно неравновесных условиях может совершаться переход от беспорядка, теплового хаоса и порядку. Могут возникать новые динамические состояния материи, отражающие взаимодействие данной системы с окружающей средой. Эти новые структуры мы назвали диссипативными структурами, стремясь подчеркнуть конструктивную роль диссипативных процессов в их образовании» [[10, с.21]].

Понятие диссипативной структуры подчеркивает «тесную и на первый взгляд парадоксальную взаимосвязь, существующую в таких ситуациях, с другой стороны между структурой и порядком, a c другой между диссипаций или потерями в классической термодинамике тепловой поток считается источником потерь. В ячейке Бернара тепловой поток становится источником порядке» [[10, c.133]].

В отличие от равновесной системы диссипативная системе не консервативна, она «открыта», т.е. она через ряд последовательных самоорганизаций усовершенствует свою структур. Структура, как вид организации и связи между элементами может изменяться, которые влияют на функциональные возможности системы.

«Винер и его коллеги считали обратную связь существенным механизмом гомеостаза саморегулирования, которое позволяет живым 
организмам поддерживать себя в состояние динамического равновесия» [[1, с.59]]. Существование двух видов обратной связи отрицательной (дающая возможность сохраниться системе) и положительная (проводящая и изменениям) позволят системе изменятся в зависимости от условий.

Диссипативные структуры, их образование и функционирование, доминируется сочетанием порядка и хаоса. Возникновение порядка в системе достигается за счет увеличения беспорядка в окружающий среде т.е. уменьшение энтропии в такой системе связано с увеличением беспорядке в окружающей среде. Обратная связь в диссипативной системе является источником возникновения новых структур, новой сложности. По концепции И.Пригожина, не только поддерживают свое устойчивое состояние вдали от равновесие, но имеют возможность развиваться. Идей процесс самоорганизации, когда в отличие от первичных возникают более сложные и более совершенные структуры.

Согласно У.Матурана и Ф.Варела «живые существа характеризуется тем, что постоянно самовоспроизводятся, именно на этой процесс самовоспроизводства мы указываем, когда называем организацию, отличающую живые существа, аутопоэтической организацией» [[6, с.12]]. Аутопоэзис присущ всем живым системам, независимо от их классов, компонентов. По мнению У.Матурана, «живая система имеет круговую организацию, она является единством взаимодействий, и именно эту кругообразность живая система должна сохранять, чтобы остаться живой системой со совершенственной ей идентичностью в различных взаимодействиях а идентичность свою она сохраняет лишь до тех пор, пока фундаментальная кругообразность, определяющая живую систему в качестве единства взаимодействий, остается не нарушенной» [[5, с.24]]. Благодаря замкнутости каузального круглого процесса, живая система допускает изменения для поддержание кругообразности, но при этом сама кругообразность остается.

У.Матурана и Ф.Варела проводят различие между организаций и структурой, структура не рассматривается как некоторой вид организации.

«Организация означает те отношение, которые должны существовать, чтобы ее можно отнести к определенному классу» [[6, с.12]]. Организация определенная конфигурация взаимоотношений между элементами единства и окружающей средой. Одна и та же организация может быть присуща различным представителем одного и тоже класса объектов. Она не зависит от свойств компонентов её составляющих, они могут быть различными. Главное отношения между компонентами должны быть в виде замкнутого каузального кругового процесса, т.е. они представляют отрицательную обратную связь, которая служит сохранению постоянства системы.

Концепция У.Матурана и Ф.Варела - новая системно-теоретическая концепция о самовоспроизводящихся системах. Самовоспроизводящиеся системы, состоящие из компонентов и отношений, способны воспроизводить и компоненты и связи между ними, с помощью лишь собственных действий, т.е. эти действия, относятся только к самой системе но не к внешнему миру. Система постоянно производит, воспроизводит, создать саму себя. В аутопоэзной системе воспроизводство и создание новых осуществляется компонентами самой системы. Поэтому организационная закрытость означает, что живая система самоорганизующаяся, поскольку ее порядок и поведение обусловлены самой системой. Но в тоже время система взаимодействует с окружающей средой, идет непрерывный обмен энергии и материи. Взаимодействие с окружающей средой не определяет организацию, она остается самоорганизующейся. Но постоянное взаимодействие с окружающий средой создает условия для формирования новых структур. «Создание новизны приводящий к развитию и эволюции, является глубоким внутренним аспектам аутопоэзиса. У.Матурана и Ф.Варела видят в различии между взаимоотношениями статических взаимоотношении

взаимоотношениями процессов ключевую разницу между физическими и биологическими компонентами» [[1]].

В аутопоэзной системе постоянно происходят структурные изменение, но при этом сохраняется организация, т.е. компоненты непрерывно или периодически распадаются и возникают, уничтожаются и создаются.

Так циклические изменения можно увидеть на таких примерах, как наша поджелудочная железа заменяет «большинство своих клеток каждые двадцать четыре часа, наши белок кровяные тельца обновляются за десять дней, а 98 процентов протеина в нашем мозге сменяются меньше, чем за месяц. Клетки нашей кожи заменяются со скоростью 100000 клеток в минуту» [[1, с.213]].

Как отмечает пресс-релиз Нобелевского комитета «Открытия Осума привели к новой парадигме в свое содержание. Его открытие путь к пониманию фундаментальной важности аутофагии для множества физиологических процессов. Таких как адаптация к голоду и ответ на инфекцию». Айтофагия генетически присуща всем живым организмам. Она позволяет клеткам 
избавляться от ненужных частей, а организм в целом от ненужных клеток.

Другой тип изменений, приводят к образованию новых структур - новые связи в аутопоэзной систем. «Изменение второго типа эволюционное, а не циклические; они тоже совершаются непрерывно, либо как последствия влияния окружающей среды, либо как результат внутренней динамики системы» [[1, с.213]]. Сложная система взаимодействий, система основываясь на циклических изменениях, сохраняет свою идентичность и изменения связаны с изменением структуры для адаптации и условиям внешней среды, сохраняя при этом свою организацию. В данном процессе наблюдается нерасторжимая связь между единство изменчивостью и организацией, различиями и сходствами. По данной концепции структурные изменения играет важную роль, как в сохранении идентичности, так и в адаптационном процессе организации. Структурные изменения, при воздействии извне трансформируются.

Структура, в данной концепции означает «те компонента и отношения, которые действительно составляют конкретное единство» [[6, с.13]].

«Посредством своей организации живая система определяет область всех взаимодействий, в которые она может вступать без утраты собственной идентичности. ... а идентичность свою она сохраняет лишь до тех пор, пока фундаментальная

кругообразность, определяющая живую систему в качестве единства взаимодействий, остается не нарушенной» [[5, с.32]].

Организация определяет область взаимодействий, структура определяет, обуславливает направление взаимодействии. Внешнее воздействие не может изменить, детерминировать системы. Она внутренне детерминирована.

Изменения, происходящие в живом существе, определяются его структурой. “Изменения, проистекающие от взаимодействия живого существа и окружающий его среды, хотя вызываются возмущающим агентом, тем не менее определяются структурой самой возмущенной системой" [[6, с.27]]. Обобщая идею аутопоэзиса можно прийти к заключению, что изменения, происходящие в аутопоэтичний системе есть выражение свойств самой системы, которая реагирует на внешнее воздейства имманентно присущим ей способом. По мнению авторов концепции имеется два положения, которые не соответствуют принципам “классический философии человек оперирует образами мира" и “отрицание окружающей среды" - отсюда вывод солингизм "согласно классической философской традиции существует только внутренняя жизнь каждого”. Но данная концепция вполне самодостаточна и устойчива. "В развернутом виде она дает убедительную картину взаимоотношений между системным единством и окружающей средой, которые характеризают не только процесс познания у живых систем, но и иные процессы, в том числе функционирование над организменных систем" [[13, с. 170]].

Действительно, в познавательном процессе положения аутопоэзной концепции не всегда соответствуют классическим, традиционным подходом гносеологии, представляют новую модель познания. В которой выдвигаются новые установки, новые идеи познавательного процессе, которые в какой-то степени перекликаются с идеями эволюционной эпистемологии «... каждое живое существо начинает с некоторой исходной структуры». Структура определяет направление взаимодействия. Биологическая структура живой системы априорна, она обладает функциональными свойствами. «... великое и фундаментальное открытие Канта: человеческое мышление и восприятие обладают определенными фундаментальными структурами до всякого индивидуального опыта» [[3]]. По Канту, вещи действуя на нас, способствуют возникновению многообразия ощущений, но вместе с этим внутренняя активность пробуждается. В концепции У.Матурана и Ф.Варела структура определяет функционирование системы «изменения, происходящие от взаимодействия живого существа и окружающей его среды, хотя вызываются возмущающим агентом, тем не менее определяются структурой самой возмущенной системы» [[6, с.27]]. Изменения. Происходящие в живых системах, детерминированы их структурой и организацией. «Понятие структурного детерминизма, введенное У.Матураной для понимания биологических систем, нашли применение впоследствии в терапии, психотерапии и даже в изучении социальных систем» [[2, с.28]].

По концепции У.Матурана и Ф.Варела, во взаимодействие вступают две независимые структуры: живое существо и окружающая среда. Между ними «с необходимостью существует структурная конгруэнтность» - (У.Матурана, Ф.Варела) т.е. между ними существует некий общий код, посредством которого так называя структурная сопряженность т.е. они структурно подогнаны соответствуют друг другу.

У.Матурана считает, что «когнитивная область - это вся область взаимодействий организма», значит увеличивал область взаимодействий мы увеличивает когнитивные возможности организма. 
Автопоэзис, это не только поддержание, сохранение, способность регенерации структур, но и также способ её| развития, самообновления. Говоря о познании в аспекте аутопоэзии можно сказать, что оно направлено на поиск того, что упущено. Определял сущность познания. Ф.Варела пишет: «Познание есть действие, направленное на нахождении того, что упущено, и восполнение недостающего с точки зрение когнитивного агента» [[6, с.6]].

\section{Заключение.}

В процессе взаимодействия и живая система и окружающая среда обоюдно активны. При наличие общего системы развиваются, адаптируется и внешней среди, изменяется и живая система и окружающая её среда. Их сосуществование обоюдное когда они совместно образуют целое называется коэволюцией. Когда между ними нет структурной конгруэнтности система не выживает.

Количество структурной сопряженности определяет способность системы адаптироваться к изменениям внешней среды. «Многоклеточные организмы имеют больше точек структурной сопряженности со средой, и вследствие этого «становятся возможными многочисленные наследственные линии, использующие разнообразные способы сохранения онтогенетической структурной связи в окружающей среде».

Эпистемологический подход определяет познание сложных явлений, поскольку выявление новых сторон требует новых подходов, новых методологических установок, которые должны адекватно отражать изучаемые явления. (Статья подготовлена в рамках гранта ОT-Ф1-95. "Возможности и перспективы междисциплинарного подхода в исследовании сложных систем” (2017-2020 г2.).

\section{References:}

1. Kapri F. (2003) Pautina jizni. Novoe nauchnoe ponimanie jivix system (razdel poryadok I bezporyadok). - Moskva: ID «Sofiya», 2003.

2. Knyazeva E.R (2011) Transdisciplinartie strategii issledovaniy // Vestnik TGPU, 2011. p.193-201.

3. Lorens K. (2001) Kantovskaya konsepsiya v svete sovremennoy biologii // Evolyusii yazik. Poznaniya. - Moskva, 2001.

4. Maynser K. (2008) Slojnisistemnoe mishlenie. Materiya. Razum. Chelovechestvo. Noviy sintez. - Moskva, 2008. -p.84.

5. Maturana U. (1996) Biologiya poznaniya // Yazik I intelekt. - Moskva, 1996. -p.24-32.

6. Maturana U., Varela F. (2001) Derevo poznaniya. Biologicheskie korni chelovecheskogo ponimanie / perevod s ang. Ya.A.Danilova. - Moskva: Progress-tradisiya, 2001. - p.13.

7. Melineskiy G.G. (2009) Sinergetika. Krizis ili razvitie. V kn. Maynsera Slojnisistemnoe mishlenie. - Moskva, 2009. -p.8.
8. Moren E. (2005) Metod. Priroda. Prirodi. Moskva, 2005. -p.134.

9. Nikolas G., Prigojin I. (1990) Poznanie slojnogo. - Moskva: Mir, 1990. - p.60.

10. Prigojin I., Stengers I. (2003) Poryadok iz xaosa. Noviy diolog cheloveka s prirodoy. Moskva, 2003. -p.21.

11. Xaken G. (1991) Informasiya i samoorganizasiya: makroskopicheskiy perexod k slojnim sistemam. - Moskva: Mir, 1991. p.28-28.

12. Xaken G. (2003) Sinergetika: uchenie o vzaimodeystvii. - Moskva-Ijevsk, 2003. p. 232 .

13. Shmerlina I.A. Maturana U., Varela F. (2003) Derevo poznaniya. Biologicheskie korni chelovecheskogo ponimanie / perevod s ang. Ya.A.Danilova. - Moskva: Progress-tradisiya, 2001. // Sosiologicheskiy jurnal, 2003. №2, p.168-179. 